\title{
Erratum to: Irrelevant sensory stimuli interfere with working memory storage: evidence from a computational model of prefrontal neurons
}

\author{
Tyler D. Bancroft • William E. Hockley • Philip Servos
}

Published online: 16 December 2012

(C) Psychonomic Society, Inc. 2012

Erratum to: Cogn Affect Behav Neurosci

DOI 10.3758/s13415-012-0131-9

On several occasions, research by Hannula et al.'s group (Hannula et al., 2010; Savolainen et al., 2011) is referred to as a vibrotactile memory study, rather than a tactile memory study. While the authors feel this does not affect their arguments, they wish to correct the error, as it is possible that readers would consider the authors' references to Hannula et al. to be slightly more favourable to their interpretation if they were vibrotactile studies, rather than non-vibrotactile tactile memory studies.

The online version of the original article can be found at http://dx.doi.org/ 10.3758/s13415-012-0131-9.

T. D. Bancroft $(\bowtie) \cdot$ W. E. Hockley $(\bowtie) \cdot$ P. Servos $(\bowtie)$

Department of Psychology, Wilfrid Laurier University,

Waterloo, Ontario N2L 3C5, Canada

e-mail: banc6110@mylaurier.ca

e-mail: whockley@wlu.ca

e-mail: pservos@wlu.ca 